\title{
Characterization of Mechanical of CTBN Liquid Rubber-Modified Epoxy Cured by Anhydride- and Amine-Based Agent
}

\author{
Harun Sepetcioglu ${ }^{1 *}$ (iD \\ 'Selçuk University, Faculty of Technology, Metallurgical and Materials Engineering Department, Konya, 42030, Turkey
}

\begin{abstract}
The main purpose of this work is to reveal the effects of carboxyl-terminated butadiene-acrylonitrile (CTBN) rubber particles on the tensile and fracture behavior of CTBN/epoxy blends cured with anhydride-and aminebased agents. In this study, $1 \mathrm{wt} . \%, 3 \mathrm{wt} . \%, 5 \mathrm{wt} . \%, 7 \mathrm{wt} . \%, 10 \mathrm{wt} . \%$ and $15 \mathrm{wt} . \%$ CTBN were added to two different epoxy systems. The CTBN/epoxy blends were prepared by ultrasonic mixing device, and curing processes were determined by DSC analysis. As CTBN fraction by weight increased in both epoxy systems, a decrease in tensile strength and modulus was detected, but deformation ability improved. The fracture toughness of CTBN/epoxy blends cured with the amine-based agent increased up to $10 \mathrm{wt} . \%$ CTBN addition. However, fracture toughness decreased when $15 \%$ by weight of CTBN was added to the epoxy matrix. The average rubber particle size was found to have a significant effect on the fracture toughness of CTBN/epoxy blends. Compared to pure epoxy, fracture toughness was increased approximately 3.5 -fold in $10 \mathrm{wt} . \%$ CTBN/epoxy blend cured with the aminebased agent. In CTBN/epoxy blends cured with the amine-based agent, CTBN shifted the reaction rate and thus it was provided better control over CTBN particle size in the CTBN/epoxy cured. The toughening mechanisms induced by CTBN, such as rubber cavitation and matrix shear banding, contributed to the enhanced fracture toughness of the CTBN/epoxy cured with the amine-based agent.
\end{abstract}

Keywords: Epoxy, CTBN, fracture toughness, tensile properties, curing agent type.

\section{INTRODUCTION}

Epoxy resins, a member of the thermoset group, have widely used as matrix materials in the production of polymer matrix composite materials [1]. The high-performance protective coatings, structural adhesives, structural materials are other areas of use. Among polymer matrices, epoxy resins are preferred over other thermoset matrices in terms of their thermal stability, mechanical properties and processability [2]. They are commonly cured with amine-based agents to form rigid network polymers [3]. However, other hardener groups such as acids and anhydrides are also used for curing epoxy resins [4]. When epoxy resins are subjected to a curing process, they form a high cross-linking rate and turn into an amorphous thermoset material. These cross-linked structures are majorly brittle. In addition, they are very poorly resistant to crack formation and growth [5]. This behavior limits their use in aerospace, defense, and automotive applications. It is a common effort to add any rubber type to the matrix to increase the toughness of the epoxy. On this topic, controlling the curing reactions to induce phase separation of the rubber has been extensively studied in the literature [4, 6-14]. Carboxy-terminated butadiene acrylo- nitrile (CTBN) was used in most of these studies to modify the epoxy. Modification methods of the epoxy matrix traditionally involve two main steps. Firstly, CTBN and epoxy are mixed, and a pre-polymer blend is obtained. Secondly, the curing agent is added to this pre-blend and then carried out to the curing process. When the toughening rigid CTBN/ epoxy network is examined under a microscope, a distribution and dispersed rubber phase in the epoxy matrix is seen. The fracture behavior of final products produced by CTBN/ epoxy blends depends on the size of the rubber particles [12, 15-17].

The Chemical bond formation is required for an efficient stress transfer between CTBN and epoxy [18]. This bond formation may occur at low and high temperatures depending on the type of curing agent. During the curing of the CTBN/epoxy blend, the separation of the rubber phase from the epoxy matrix occurs. The molecular weight of the epoxy increases with the decrease of the configurational entropy in the curing process [19-23]. It leads to a decrease in the solubility of CTBN with the increase of the molecular weight of the epoxy. Chemical reactions controlling crosslink density between epoxy and curing agent are effective 
in the precipitation of rubber particles. In addition, the particle size and distribution of rubbers formed in the epoxy matrix depend on the curing procedure and the interaction between the rubber and epoxy resin [24-26].

The epoxy systems are used in the polymer industry. The mechanical properties of the final product produced with these systems depend on the nature of the curing agent used, and anhydride- and amine-based curing agents are widely used in the composite industry. The aim of the study is to investigate the tensile and fracture properties of CTBN/epoxy cured with anhydride- and amine-based curing agents. The mechanical properties of the blends depend on the homogeneous dispersion of CTBN in epoxy and the curing and post-curing processes. The fracture tests by using linear fracture mechanics (LEFM), and tensile tests were carried out on the blends. Relationships between fracture toughness and the average rubber particle size have been reported.

\section{MATERIALS AND METHODS}

\subsection{Materials}

For this study, diglycidyl ether of bisphenol A resins with low viscosity in the two different standards (trade name;

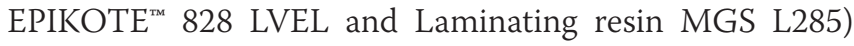
were preferred. Hexahydrophthalic anhydride (trade name; EPIKURE $^{\mathrm{TM}}$ H866) and 3-aminomethyl-3,5,5-trimethylcyclohexylamine (trade name; L285) are curing agents of these epoxy resins.

\begin{tabular}{|c|c|} 
Table 1. The properties of the CTBN liquid rubber \\
\begin{tabular}{|c|c|}
\hline Properties & Values \\
\hline Viscosity, $\left(40^{\circ} \mathrm{C}\right)$ Pa.s & $7-12$ \\
\hline Carboxyl content, $\mathrm{mmol} / \mathrm{g}$ & $0.58 \sim 0.65$ \\
\hline Nitrile group content, $\%$ & $8.0 \sim 12.0$ \\
\hline Water content, $\% \leq$ & 0.05 \\
\hline Volatile content, $\% \leq$ & 2.0 \\
\hline
\end{tabular}
\end{tabular}

To modify the epoxy, the liquid rubber used is carboxyl-terminated butadiene-acrylonitrile copolymer (CTBN) purchased from Zibo Qilong, China. The properties of CTBN liquid rubber given in Table 1.

(a)<smiles>COCCOc1ccc(C(C)(C)c2ccc(OCC3COC3)cc2)cc1</smiles>

(b)

(c)<smiles>CC1(C)CC(N)CC(C)(CN)C1</smiles>

(d)<smiles>N#CC(=CCC=CCC(=O)O)CCC(=O)O</smiles>

Figure 1. The chemical structure of components (a) diglycidyl ether of bisphenol A (DGEBA), (b) 3-aminomethyl-3,5,5-trimethylcyclohexylamine, (c) hexahydrophthalic anhydride and (d) carboxyl terminated butadiene acrylonitrile (CTBN) used in this study.

\subsection{Production of epoxy/CTBN blends}

$0,1,3,5,7,10$, and 15 wt.\% CTBN was added to the MGS LR285 and the 828 LVEL epoxy resins. The CTBN/MGS LR285 and CTBN/828 LVEL blends were heated up to $25^{\circ} \mathrm{C}$ and $60^{\circ} \mathrm{C}$, respectively. Afterward, both blends were mixed together continuously until a clear blend was obtained, then the blends were degassed at $25^{\circ} \mathrm{C}$ by vacuum for about 10 minutes. After, it was used curing processes, offering the high mechanical properties provided by the resin manufacturers for both the blends. A stoichiometric amount of amine-based L285 and anhydride-based H866 curing agents were added to CTBN/MGS LR285 and CTBN/828 LVEL blends, respectively. Both blends containing curing agents were stirred slowly. The CTBN/MGS LR285/L285 blends were cured at $60{ }^{\circ} \mathrm{C}$ for 1 hour, and then post-cured for 3 hours at $90{ }^{\circ} \mathrm{C}$. Then, the other CTBN/828 LVEL/H866 blends were cured at $120^{\circ} \mathrm{C}$ for 3 hours, and then post-cured for 3 hours at $150{ }^{\circ} \mathrm{C}$. The ratios of components in CTBN/ epoxy blends cured by anhydride- and amine-based were given in Table 2 and Table 3, respectively.

Table 2. The ratios of CTBN/epoxy blends cured by anhydride-based

\begin{tabular}{|c|c|c|c|c|c|}
\hline $\begin{array}{c}\text { Sample } \\
\text { Codes }\end{array}$ & $\begin{array}{c}\text { Trade } \\
\text { name of } \\
\text { resin }\end{array}$ & $\begin{array}{c}\text { Trade name } \\
\text { of curing } \\
\text { agent }\end{array}$ & $\begin{array}{c}\text { Bisphenol-A } \\
\text { Epoxy resin, } \\
\text { wt. } \%\end{array}$ & $\begin{array}{l}\text { CTBN*, } \\
\text { wt.\% }\end{array}$ & $\begin{array}{c}\text { Anhydri- } \\
\text { de-based } \\
\text { curing agent } \\
\text { wt. } \%\end{array}$ \\
\hline $8 \mathrm{H} 0$ & \multirow{7}{*}{828 LVEL } & \multirow{7}{*}{ H866 } & \multirow{7}{*}{80} & 0 & \multirow{7}{*}{20} \\
\hline $8 \mathrm{H} 1$ & & & & 1 & \\
\hline $8 \mathrm{H} 3$ & & & & 3 & \\
\hline $8 \mathrm{H} 5$ & & & & 5 & \\
\hline $8 \mathrm{H} 7$ & & & & 7 & \\
\hline $8 \mathrm{H} 10$ & & & & 10 & \\
\hline $8 \mathrm{H} 15$ & & & & 15 & \\
\hline
\end{tabular}

* 0-15 wt.\% CTBN was added onto the combination of the curing agent/ epoxy in stoichiometric amount (20/80).

Table 3. The ratios of CTBN/epoxy blends cured by amine-based

\begin{tabular}{|c|c|c|c|c|c|}
\hline $\begin{array}{c}\text { Sample } \\
\text { Codes }\end{array}$ & $\begin{array}{l}\text { Trade } \\
\text { name of } \\
\text { resin }\end{array}$ & $\begin{array}{c}\text { Trade } \\
\text { name of } \\
\text { curing } \\
\text { agent }\end{array}$ & $\begin{array}{c}\text { Bisphenol-A } \\
\text { Epoxy resin, } \\
\text { wt. } \%\end{array}$ & $\begin{array}{l}\text { CTBN*, } \\
\text { wt.\% }\end{array}$ & $\begin{array}{l}\text { Amine-ba- } \\
\text { sed } \\
\text { curing agent } \\
\text { wt. } \%\end{array}$ \\
\hline MLO & \multirow{7}{*}{$\begin{array}{c}\text { MGS } \\
\text { LR285 }\end{array}$} & \multirow{7}{*}{ L285 } & \multirow{7}{*}{60} & 0 & \multirow{7}{*}{40} \\
\hline ML1 & & & & 1 & \\
\hline ML3 & & & & 3 & \\
\hline ML5 & & & & 5 & \\
\hline ML7 & & & & 7 & \\
\hline ML10 & & & & 10 & \\
\hline ML15 & & & & 15 & \\
\hline
\end{tabular}

* 0-15 wt.\% CTBN was added onto the combination of the curing agent/ epoxy in stoichiometric amount (40/60).

\subsection{Mechanical characterization}

The static tensile properties of the composites were determined at room temperature $\left(24^{\circ} \mathrm{C}\right)$ using a Shimadzu tester (AGS-X Series) with a crosshead speed of $2 \mathrm{~mm} / \mathrm{min}$, according to ASTM D638. Three samples of each composition were tested, and the average value and standard deviation were reported. The Mode-I critical stress intensity factor $\left(\mathrm{K}_{\mathrm{IC}}\right)$ was measured using single edge notched bend (SENB) samples of $10 \times 20 \times 88 \mathrm{~mm}^{3}$, which ensures the plane 
strain condition according to ASTM D5045. Dimensions of tensile and fracture test samples used in mechanical characterization were given in Figure 2. The SENB sample and three-point flexural test fixture used in the fracture toughness measurements were shown in Figure 3.

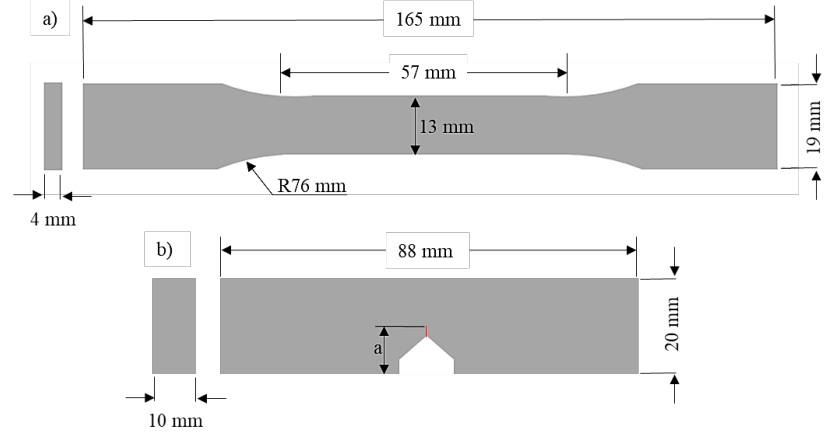

Figure 2. Dimensions of tensile (a) and fracture (b) test samples used in mechanical characterization

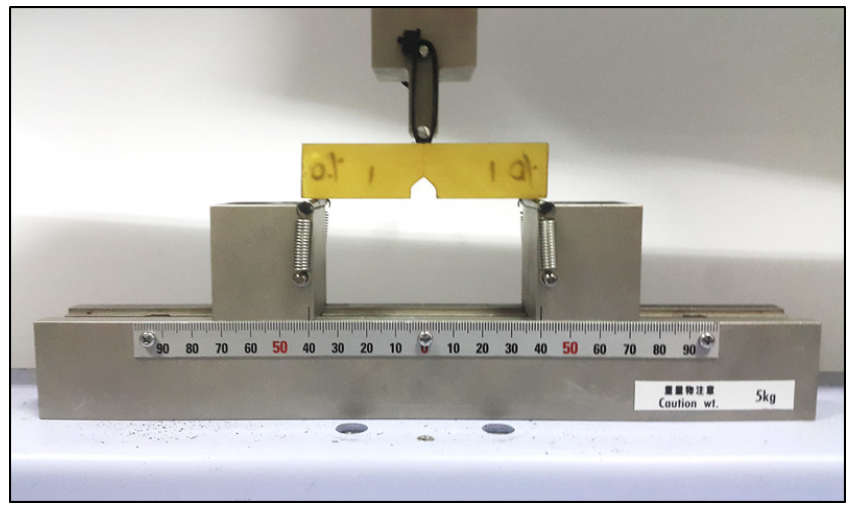

Figure 3. Fracture toughness measurements on SENB sample

The sharp crack was generated by a fresh razor blade, which was fixed to tool holder of universal milling machine, on the notch in the middle of the rectangular bar. The fracture tests were conducted on the same Shimadzu tester at a crosshead speed of $10 \mathrm{~mm} / \mathrm{min}$. The $\mathrm{K}_{\mathrm{IC}}$ values were calculated using the following relationship:

$$
\begin{aligned}
& K_{Q}=\left(\frac{P_{Q}}{B W^{1 / 2}}\right) f(x) \\
& f(x)=6 x^{1 / 2} \frac{\left[1.99-x(1-x)\left(2.15-3.93 x+2.7 x^{2}\right)\right]}{(1+2 x)(1-x)^{3 / 2}} \\
& x=a / W \\
& B, a, W-a \geqslant 2.5\left(\frac{K_{Q}}{\sigma_{Y S}}\right)^{2}
\end{aligned}
$$

where, $K_{Q}$ is a provisional fracture toughness, $f(x)$ the shape factor, $\mathrm{P}_{\mathrm{Q}}$ the peak load, $\mathrm{B}$ the sample thickness, $\mathrm{W}$ the sample width, a the crack length, $\sigma_{\mathrm{YS}}$ the yield strength. Eq. (4) was satisfied for the dimensions of produced SENB samples. The SENB samples were loaded up to break on a Shimadzu tester (AGS-X Series) under a crosshead speed of $10 \mathrm{~mm} /$ min. The value of the strain energy release rate $\left(G_{I C}\right)$ was calculated from the knowledge of the values of $\mathrm{K}_{\mathrm{IC}}$ and $\mathrm{E}$, using the relationship:

$$
K_{I C}^{2}=\left(\frac{E G_{I C}}{\left(1-v^{2}\right)}\right)
$$

where $v$ is the Poisson's ratio and was taken to be 0.35 in value $[27,28]$.

\subsection{Differential scanning calorimetry analysis}

Differential scanning calorimetric (DSC) analysis was employed to study the curing processes of the pure epoxy and 10 wt.\% CTBN/epoxy blend. The DSC measurements were performed with a METTLER TOLEDO DSC 1-STAR System calorimeter by using a computer for data acquisition. Isothermal heating measurements were carried out in a nitrogen flow of $50 \mathrm{ml} / \mathrm{min}$. The heating was made from $25^{\circ} \mathrm{C}$ to the temperature of the isotherm at a heating rate of $5{ }^{\circ} \mathrm{C} /$ min. The curing process of the pure epoxy and CTBN/epoxy blends govern the mechanical and thermal properties that are crucial in applications.

\subsection{Examination of Fracture Surfaces}

Dispersion and distribution of rubber particles in the fracture surfaces of CTBN/epoxy blends was studied with a Nikon optical microscope. To obtain microstructures showing the dispersion and distribution of particles, TSView that is a modular software specialized for image acquisition, processing and analysis was used. The fracture surface scrutiny of samples was achieved with image acquisition and image processing modules of the software. The average particle size was defined by measuring the sizes of 20 randomly chosen the rubber particles from acquired the microstructure images.

\section{RESULTS AND DISCUSSION}

\subsection{Tensile Properties}

The stress-strain curves of pure epoxy and CTBN/epoxy blends cured with anhydride-and amine-based curing agents are shown in Figure 4 and Figure 5, respectively. The significant tensile properties calculated from these curves are presented in Table 4 and Table 5 . It is well known from the literature $[10,13,15,29,30]$ that modification of epoxy with rubber decreases the tensile strength and elasticity modulus. Generally, this reduction is attributed to the low modulus of elasticity of the rubber phase and the reduction of the crosslink density of the epoxy during curing. As expected, the tensile strength and modulus of elasticity of pure epoxy and CTBN/epoxy blends cured with both curing agents decreased as the rate of CTBN addition by weight increased. As seen from Figure 4, the strain of epoxy increased with the addition of $7 \mathrm{wt} . \%$ and $10 \mathrm{wt} . \%$ CTBN/epoxy cured by anhydrite-based agent.

The inclusion of 1 wt.\% and 3 wt.\% CTBN in the epoxy cured by amine-based agent led to increases in the strain, as shown in Figure 5. Moreover, the tensile strength and elasticity modulus of the CTBN/epoxy matrix slightly decreases with the addition of $1 \mathrm{wt} . \%$ and 3 wt.\% CTBN, whereas a major increase in the strain was observed at the same sam- 
ples. The ductility of the epoxy matrix can be achieved by reducing the crosslink density [31]. In addition, the crosslink density is affected by the epoxy equivalent weights of the epoxies. Pearson and Yee [32] examined the effect of the epoxy equivalent by varying the crosslink density of CTBN/epoxy blends cured with different DDS. They reported greater ductility with low cross-linked epoxies.

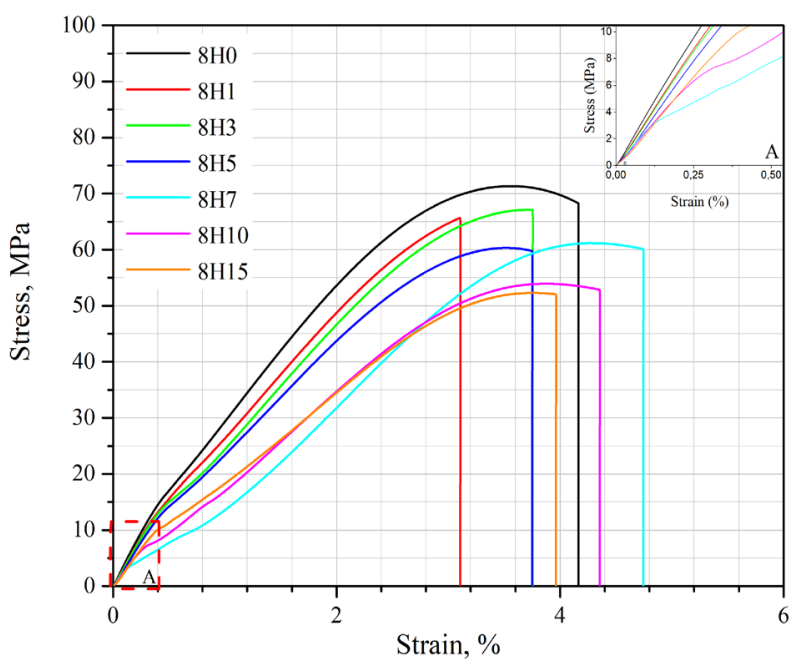

Figure 4. The stress-strain curves of pure epoxy and CTBN/epoxy blends cured by anhydrite-based agent

Table 4. Tensile test results of CTBN/epoxy blends cured by anhydride-based agent

\begin{tabular}{|c|c|c|c|}
\hline $\begin{array}{c}\text { Sample } \\
\text { Codes }\end{array}$ & $\begin{array}{c}\text { Tensile Strength } \\
(\sigma), \mathrm{MPa}\end{array}$ & $\begin{array}{c}\text { Strain }(\epsilon), \\
\%\end{array}$ & $\begin{array}{c}\text { Modulus }(\mathrm{E}), \\
\mathrm{GPa}\end{array}$ \\
\hline $8 \mathrm{H} 0$ & $72.58 \pm 3.21$ & $4.06 \pm 0.58$ & $3.00 \pm 0.05$ \\
\hline $8 \mathrm{H} 1$ & $66.80 \pm 2.98$ & $3.16 \pm 0.34$ & $2.92 \pm 0.04$ \\
\hline $8 \mathrm{H} 3$ & $64.23 \pm 4.08$ & $3.93 \pm 0.22$ & $2.88 \pm 0.01$ \\
\hline $8 \mathrm{H} 5$ & $63.08 \pm 2.87$ & $3.84 \pm 0.17$ & $2.69 \pm 0.05$ \\
\hline $8 \mathrm{H} 7$ & $63.77 \pm 1.26$ & $4.37 \pm 0.97$ & $2.52 \pm 0.03$ \\
\hline $8 \mathrm{H} 10$ & $54.13 \pm 5.33$ & $4.26 \pm 0.55$ & $2.33 \pm 0.05$ \\
\hline $8 \mathrm{H} 15$ & $52.99 \pm 2.29$ & $3.88 \pm 0.15$ & $2.08 \pm 0.05$ \\
\hline
\end{tabular}

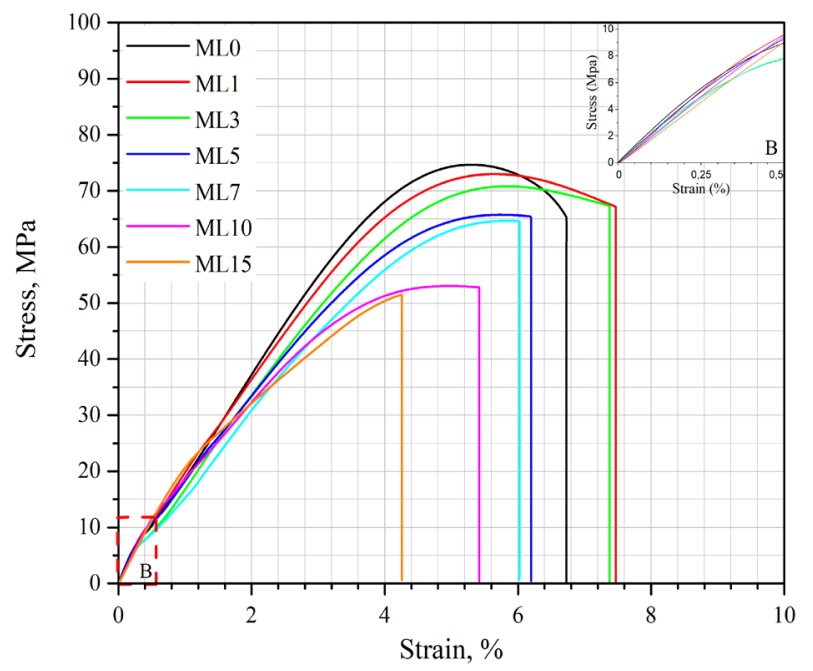

Figure 5. The stress-strain curves of pure epoxy and CTBN/epoxy blends cured by amine-based agent
Table 5. Tensile test results of CTBN/epoxy blends cured by amine-based agent

\begin{tabular}{|c|c|c|c|}
\hline $\begin{array}{c}\text { Sample } \\
\text { Codes }\end{array}$ & $\begin{array}{c}\text { Tensile Strength } \\
(\sigma), M P a\end{array}$ & $\begin{array}{c}\text { Strain }(\epsilon), \\
\%\end{array}$ & $\begin{array}{c}\text { Modulus }(E), \\
\text { GPa }\end{array}$ \\
\hline ML0 & $76.89 \pm 3.21$ & $6.78 \pm 0.78$ & $3.20 \pm 0.05$ \\
\hline ML1 & $75.91 \pm 1.09$ & $7.54 \pm 1.99$ & $3.05 \pm 0.01$ \\
\hline ML3 & $69.31 \pm 1.30$ & $7.43 \pm 1.28$ & $3.01 \pm 0.04$ \\
\hline ML5 & $64.99 \pm 0.69$ & $6.28 \pm 1.77$ & $2.97 \pm 0.02$ \\
\hline ML7 & $64.63 \pm 0.62$ & $5.93 \pm 1.02$ & $2.96 \pm 0.03$ \\
\hline ML10 & $52.86 \pm 1.36$ & $5.57 \pm 0.75$ & $2.94 \pm 0.05$ \\
\hline ML15 & $50.85 \pm 0.95$ & $4.33 \pm 0.21$ & $2.86 \pm 0.02$ \\
\hline
\end{tabular}

The ductility value increased more in ML1 and ML3 samples with lower CTBN content than the 8H7 and 8H10 samples with high CTBN content. It can be said that less crosslink density occurs at low rubber content in CTBN/epoxies produced with the amine-based agent. Compared to the CTBN/epoxy blends cured by anhydrite- and amine-based agent, the blends cured by amine-based agent presents higher tensile strength, strain at break and elasticity modulus. The mechanical properties of the CTBN/epoxy blends cured by amine-based agent were found to be more consistent and higher compared to using an anhydrite-based agents.

\subsection{Fracture toughness}

For pure epoxy and CTBN/epoxy blends cured with anhydride- and amine-based agents, fracture toughness $\left(\mathrm{K}_{\mathrm{IC}}\right)$ and critical strain energy release rate $\left(\mathrm{G}_{\mathrm{IC}}\right)$ are given in Figure 6 and Figure 7, respectively. The 8H0 and MLO samples show low fracture toughness of $1.24 \pm 0.05 \mathrm{MPam}^{1 / 2}$ and $0.80 \pm 0.30 \mathrm{MPam}^{1 / 2}$ respectively. The addition of CTBN to the epoxy cured with the amine-based agent significantly increased the $\mathrm{K}_{\mathrm{IC}}$ to $2.66 \pm 0.78 \mathrm{MPam}^{1 / 2}$, approximately 3.5 times. However, the enhancement in fracture toughness could not be achieved with CTBN/epoxy blends cured by the anhydride-based agent. The $\mathrm{K}_{\mathrm{IC}}$ and $\mathrm{G}_{\mathrm{IC}}$ values gradually decreased as CTBN was added to the anhydride/epoxy system. The presence of CTBN in the amine/epoxy system progressively increased fracture toughness but a decrease in $\mathrm{K}_{\mathrm{IC}}$ was observed with the addition of more than $10 \%$ by weight of CTBN. The improvement in fracture toughness has been attributed to matrix shear banding [33], cavitation [34], and rubber fractures [35]. In addition, the stress dissipation between the rubber phase and polymer chains is improved due to the percolation of rubber particles in the epoxy matrix. This improvement restricts crack growth leading to increased fracture toughness [30]. As shown in Table 5, the improvements in fracture toughness of CTBN/ epoxy blends were within $70-300 \%$ in literature studies [13, 14, 24, 26, 30, 36, 37].

The CTBN modification at rates ranging from $5-15 \%$ by weight has shown remarkable results in terms of increased toughness. When more than $15 \mathrm{wt}$ \% CTBN is added to pure epoxy, it was seen a trend for a decrease in the toughness of the epoxy due to rubber agglomeration and phase inversion [38]. This demonstrates that the CTBN curing effect reveals its saturation and reactive rubber types as a liquid rubber 
modifier are a useful method for obtaining polymer blends with high fracture toughness. The effects of rubber particle size on the toughness of both epoxy systems modified with CTBN were analyzed over fracture surface studies and toughening mechanisms and discussed in the subsequent section.

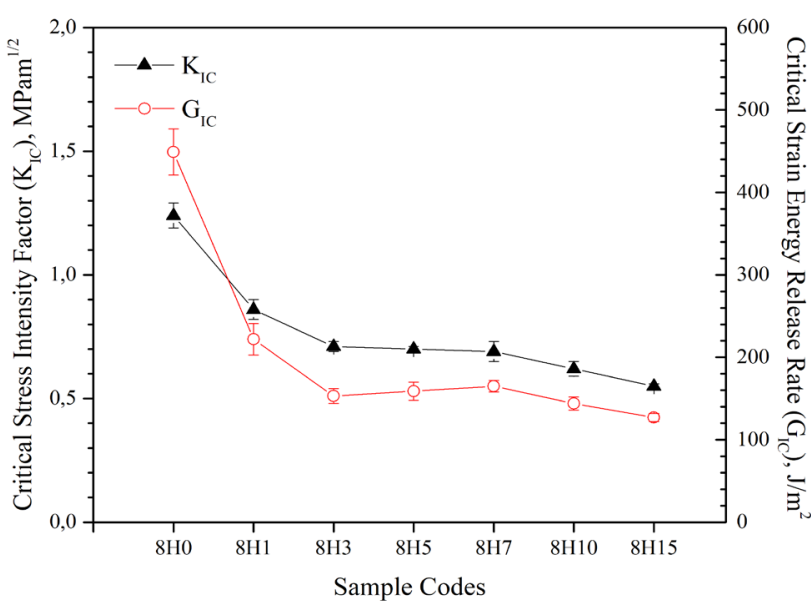

Figure 6. Fracture toughness $\left(\mathrm{K}_{1}\right)$ and critical strain energy release rate $\left(G_{1 C}\right)$ of pure epoxy and its CTBN blends cured by anhydrite-based agent

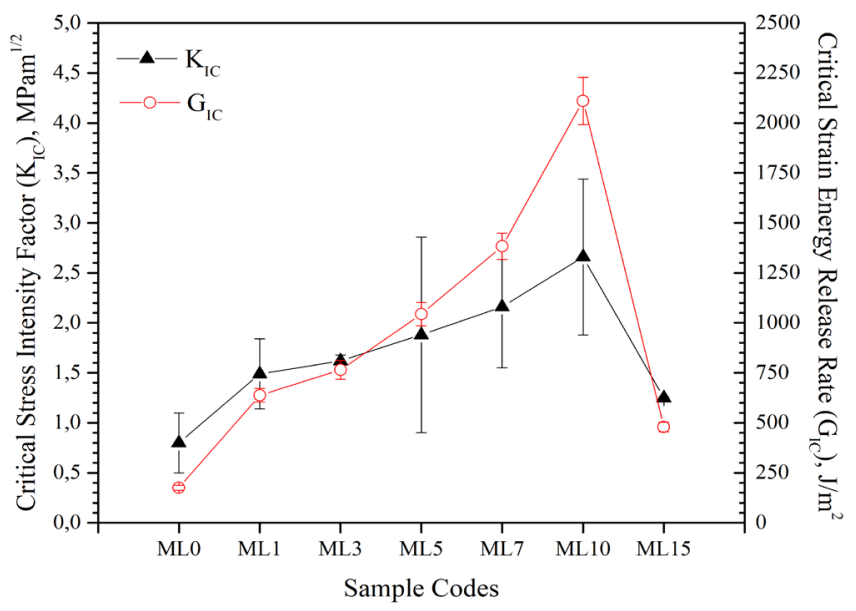

Figure 7. Fracture toughness $\left(\mathrm{K}_{\mathrm{IC}}\right)$ and critical strain energy release rate $\left(G_{\mathrm{IC}}\right)$ of pure epoxy and its CTBN blends cured by amine-based agent

Table 5. The increases in fracture toughness of CTBN epoxy blends according to related literature

\begin{tabular}{|c|c|c|c|c|c|}
\hline References & $\begin{array}{c}\text { Rubber } \\
\text { Types }\end{array}$ & $\begin{array}{l}\text { Rubber } \\
\text { Content }\end{array}$ & $\begin{array}{l}\text { Fracture tou- } \\
\text { ghness of pure } \\
\text { epoxy, } \\
\left(\mathrm{K}_{\mathrm{IC}}\right), \mathrm{MPa} \mathrm{m}^{1 / 2}\end{array}$ & $\begin{array}{l}\text { Fracture tough- } \\
\text { ness of CTBN/ } \\
\text { epoxy blend, } \\
\left(\mathrm{K}_{\mathrm{IC}}\right), \mathrm{MPa} \mathrm{m}^{1 / 2}\end{array}$ & $\begin{array}{c}\text { Incre- } \\
\text { ase, } \\
\%\end{array}$ \\
\hline Wang et al [13] & CTBN & 10 wt.\% & 0.75 & 1.28 & 70.7 \\
\hline Zhang et al [14] & CTBN & 10 wt.\% & 0.77 & 1.47 & 90.8 \\
\hline Tripathi et al [30] & CTBN & 15 wt.\% & 0.90 & 3.6 & 300 \\
\hline Chikhi et al [24] & ATBN* & $12.5 \mathrm{phr}$ & 0.90 & 1.5 & 66.7 \\
\hline Thomas et al [26] & HTPB* $^{*}$ & 10 wt.\% & 0.90 & 2.5 & 178 \\
\hline Yahyaie et al [37] & ETPB* & 7.5 wt. $\%$ & 0.65 & 1.80 & 176 \\
\hline Saleh et al [36] & LENR* $^{*}$ & 5 wt.\% & 0.80 & 3.1 & 288 \\
\hline This study & CTBN & 10 wt.\% & $0.80 \pm 0.30$ & $2.66 \pm 0.78$ & 202 \\
\hline
\end{tabular}

*Amine-terminated butadiene acrylonitrile (ATBN), Hydroxyl-terminated polybutadiene (HTPB), Epoxy-terminated polybutadiene (ETPB), Epoxidized natural rubber (LENR)

\subsection{Effect of Rubber Particle Size}

The growth of rubber particles in the epoxy matrix is affected by the curing reaction rate of the epoxy [23]. $10 \mathrm{wt} . \%$ CTBN modified epoxy blend were cured with both aminebased and anhydride-based agents and analyzed by DSC. Figure 8 shows the accelerating effect of $10 \mathrm{wt}$.\% CTBN carboxyl groups on the curing of amine/epoxy and anhydride/ epoxy. The presence of CTBN in the epoxy matrix shifts the peak exotherm. With the increased reaction rate, these peaks are shifted to lower temperatures, while are shifted to higher temperatures with decreasing reaction rates. It was found that the peak exotherm did not change in the CTBN/ epoxy blend cured by anhydride-based agent.

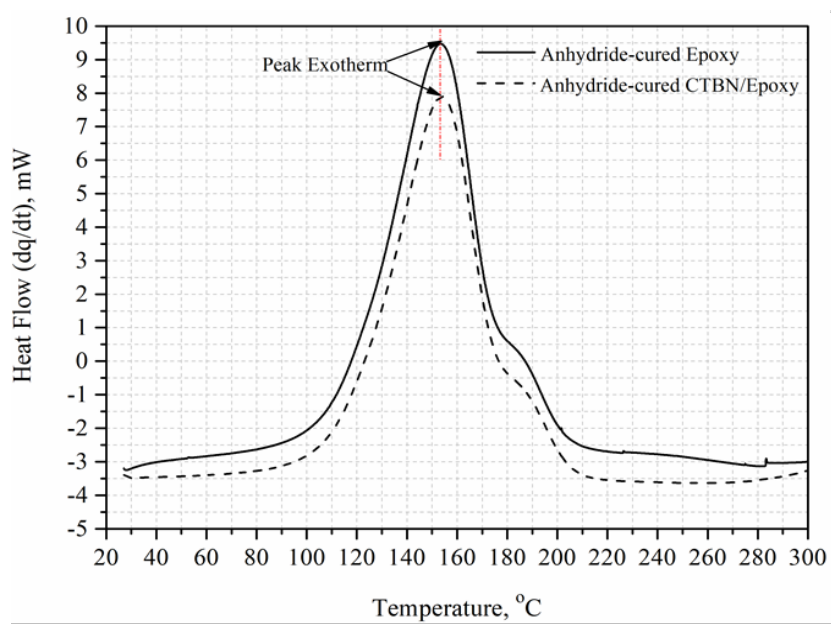

(a)

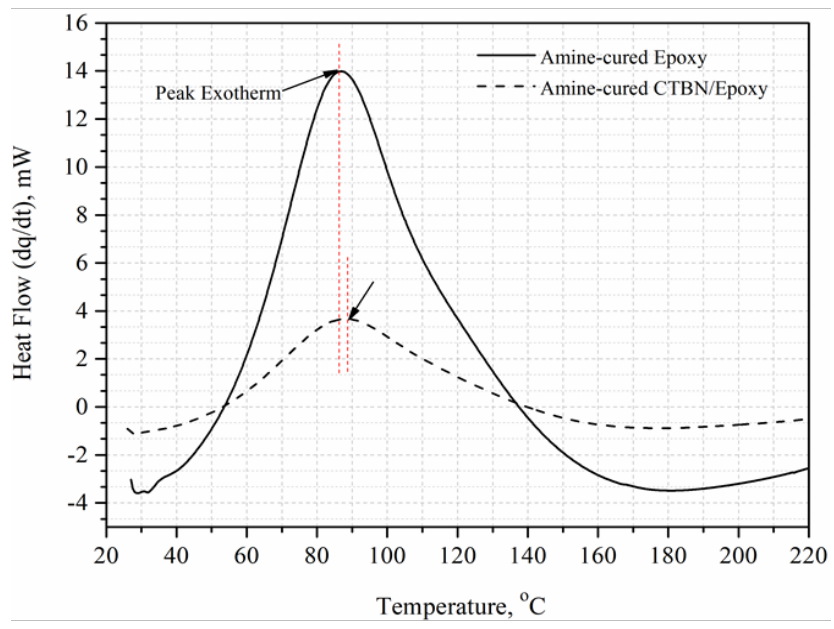

(b)

Figure 8. DSC scanning of 10 wt.\% CTBN modified and unmodified anhydrite/epoxy (a) and amine/epoxy (b) systems

It was concluded that the reaction rate in the anhydride/epoxy system was not affected by the presence of CTBN. In the CTBN/epoxy blend cured by amine-based agent, the peak exotherm was shifted to a higher temperature. The presence of CTBN reduced the curing reaction rate in the amine-epoxy system. In the anhydride/epoxy system, the heat of polymerization slightly decreased. This confirms that the final reaction status for CTBN is not significantly affected by 
the presence of CTBN. It was observed that the heat of polymerization was reduced dramatically with the addition of CTBN in the amine/epoxy system.

In CTBN/epoxy blends cured with anhydride- and aminebased agents, the average size (APS) of rubber particles formed by the phase separation mechanism [22] in the epoxy matrix was affected by the CTBN ratio by weight. Figure 9 shows the change of fracture toughness with APS according to the curing agent type. The APS of $8 \mathrm{H} 1,8 \mathrm{H} 3$ $8 \mathrm{H} 5,8 \mathrm{H} 7,8 \mathrm{H} 10$ and $8 \mathrm{H} 15$ samples was obtained in about $0.10,0.32,0.53,0.67,0.95$ and 0.37 micron, respectively. The APS increased up to $10 \mathrm{wt} . \%$ CTBN rate but decreased after this rate. Figure 10 shows that the rubber particle is homogeneously distributed in the matrix in the $8 \mathrm{H} 1$ and $8 \mathrm{H} 5$ samples compared to the $8 \mathrm{H} 10$ and $8 \mathrm{H} 15$ samples. The APS in $8 \mathrm{H} 1$ and $8 \mathrm{H} 5$ samples are close to each other. However, in the $8 \mathrm{H} 10$ and $8 \mathrm{H} 15$ samples, the rubber particles were dispersed in the matrix with different APS. The CTBN ratio in the samples cured by anhydride-based agent affected the size and distribution of the particles. However, it did not contribute to increasing the fracture toughness of the epoxy. As the weight of the CTBN ratio increased in anhydride/ epoxy systems, fracture toughness gradually decreased.

The average particle sizes of ML1, ML3, ML5, ML7, ML10 and ML15 samples were obtained in about 0.12, 0.37, 0.61, 2.7, 7.3 and 4.5 micron, respectively. As with the samples cured by anhydride-based agent, APS first increased up to 10 wt.\% CTBN, but a decrease was detected after this rate. Figure 11 shows that the rubber particles in ML1, ML5 and ML10 samples are homogeneously distributed into the matrix, except for the ML15 sample. The CTBN ratio in the samples cured by amine-based agent affected the size and distribution of the particles. In contrast to the samples cured by anhydride-based agent, the rise of the CTBN ratio contributed to increasing the fracture toughness of the epoxy. As the weight of the CTBN ratio increased in amine/epoxy systems except for the $15 \mathrm{wt} . \%$ CTBN ratio, fracture toughness gradually increased.

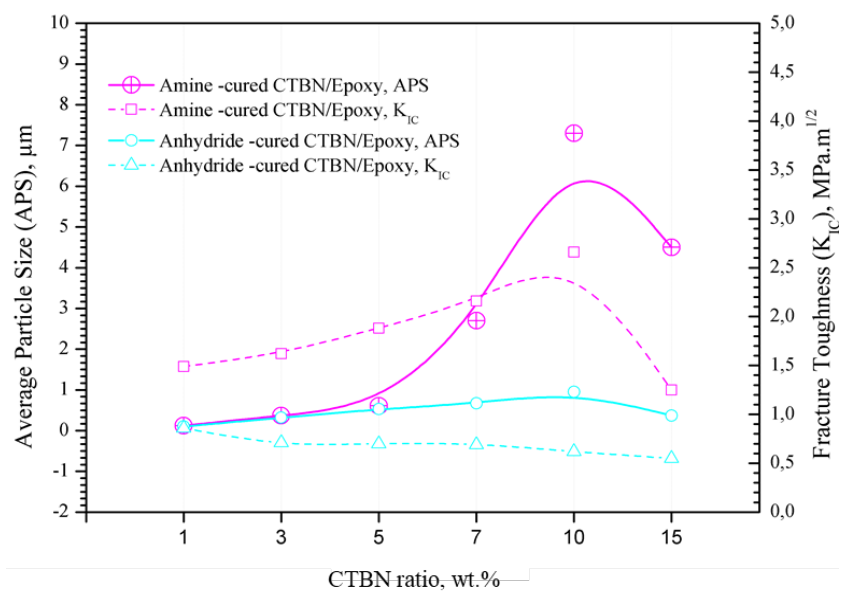

Figure 9. Comparison of average rubber particle size versus and fracture toughness versus CTBN ratios

The effect of CTBN modification had different results on fracture toughness of anhydride/epoxy and amine/epoxy systems. The morphology of CTBN/epoxy blends cured at different temperatures is shown in Figure 10 and Figure 11. The APS of rubbers formed in CTBN/epoxy blends decreased as the isothermal curing temperature increased, and larger APS of rubber was observed in optical micrographs of epoxy mixtures cured at a lower temperature. The phase separation in epoxy/rubber blends occurs at a constant temperature. The rubber phase separation is initiated by the reaction caused curing agent. The phase separation has been reported to progress through the mechanism of nucleation and growth in the epoxy matrix $[39,40]$. The curing rate in epoxy systems cured by anhydride-based agent is extremely high at elevated temperatures. A high curing temperature leads to a higher viscosity at the initiating of rubber phase separation. This leads to the diffusion difficulty required for the growth of rubber particles [41]. Therefore, in the anhydride/epoxy system, under the effect of a high curing temperature, the degree of phase separation was low, resulting in a low APS of the rubber formed. The rubber APS in epoxy/rubber blends is determines by the reaction kinetics in which the curing agent is involved. Therefore, the fracture behavior of epoxy/rubber blends depending on APS should be investigated experimentally.

\section{CONCLUSIONS}

The CTBN modification effect on the tensile and fracture properties of CTBN/epoxy blends cured by anhydride- and amine-based agent was investigated, and the results obtained from the study were summarized below:

1. The curing temperature is a necessary procedure for obtaining the optimal toughening effect of rubber, particularly in epoxies cured by anhydrite-based agent. The anhydride/ epoxy systems cured at high temperatures of $120{ }^{\circ} \mathrm{C}$ cause smaller rubber particle sizes compared to amine/epoxy systems cured at low curing temperatures of $90{ }^{\circ} \mathrm{C}$. Therefore, the presence of the rubber phase, which has relatively small particle sizes in the epoxy matrix, decreases the fracture toughness.

2. The fracture toughness is dependent on CTBN rubber particle size and distribution.

3. The fracture toughness of CTBN/epoxy blends cured by anhydride-based agent decreased as CTBN addition increased in the epoxy matrix.

4. In fracture surfaces examination, large rubber particles have been found to be more effective than small particles in producing an enriched toughness effect.

5. The microstructure of the dispersed particles in the CTBN modified anhydrite/epoxy system was not found to be significantly changed by different CTBN content.

6. In amine/epoxy systems cured at low curing temperatures, CTBN decreased the cross-linking reaction rate by shifting the exotherm peak to high temperature. This situa- 


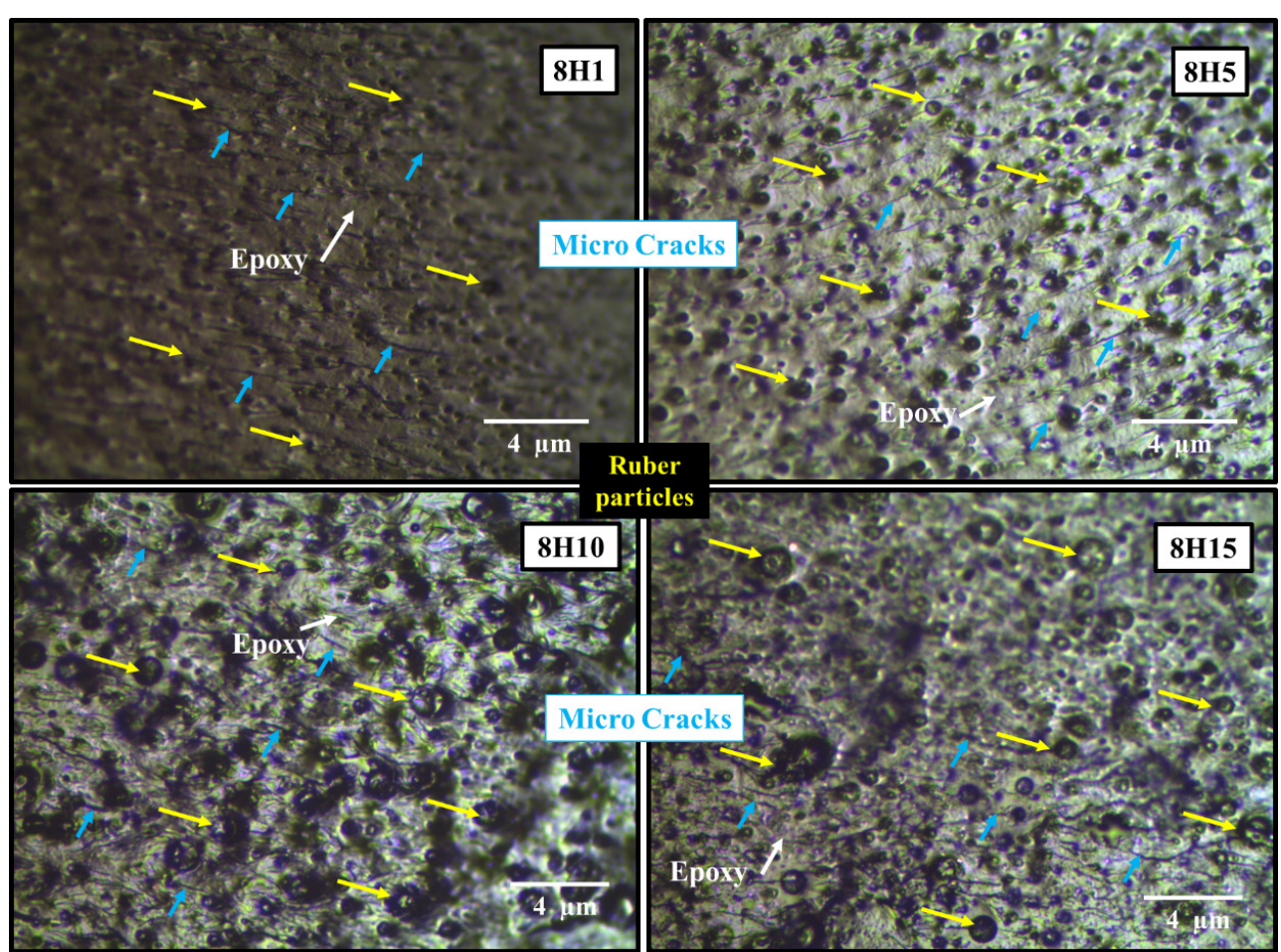

Figure 10. The optical microscope images of the fracture surfaces of CTBN/epoxy blends cured by anhydride -based agent.
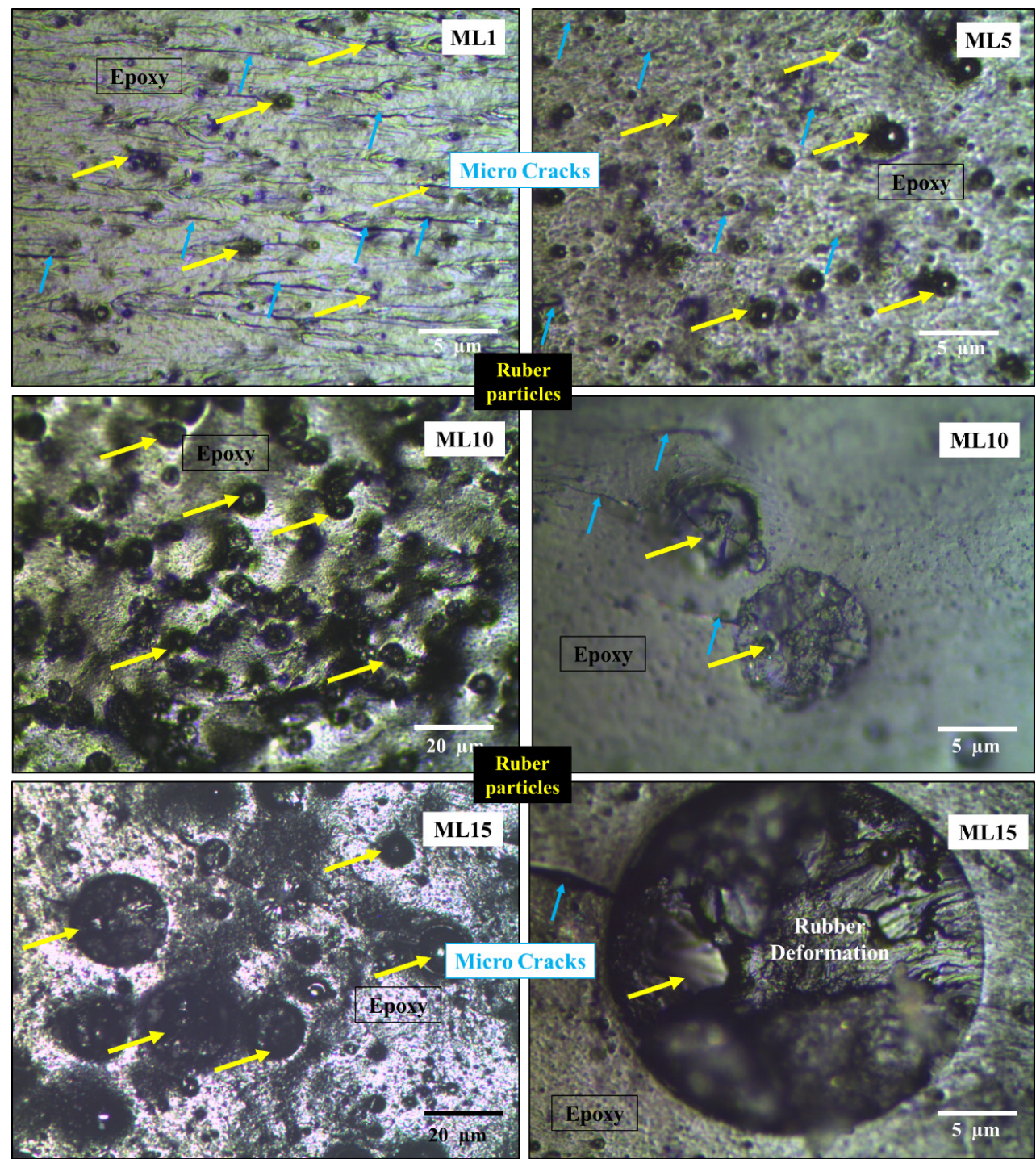

Figure 11. The optical microscope images of the fracture surfaces of CTBN/epoxy blends cured by amine-based agent. 
tion had a positive effect on the growth of rubber particles. However, the exotherm peak did not shift in anhydride/epoxy systems, so this effect was not observed.

7. It was found from optic micrographs that the average size of rubber particles in the $10 \mathrm{wt} \%$ CTBN modified anhydrite/ epoxy system was $0.95 \mu \mathrm{m}$, which is smaller than the average size of rubber particles for the $10 \mathrm{wt} . \%$ CTBN modified amine/epoxy system $(7.3 \mu \mathrm{m})$.

8. As the CTBN rate increased in anhydride/epoxy and amine/epoxy systems, a decrease in tensile strength and elasticity modulus was found. The deformation abilities of both epoxy systems were improved by the optimized addition of CTBN.

\section{REFERENCES}

[1] Aslan, A., Salur, E. (2021). Düzcükoğlu H, Şahin ÖS, Ekrem M. The effects of harsh aging environments on the properties of neat and MWCNT reinforced epoxy resins. Construction and Building Materials. 272:121929.

[2] Lee, H., Neville, K. (1967). Handbook of epoxy resins.

[3] Lee, LJ. (1989). Modeling and coputer simulation of reactive processing.

[4] Thomas, R., Durix S, Sinturel C, Omonov T, Goossens S, Groeninckx $G$, et al. (2007). Cure kinetics, morphology and miscibility of modified DGEBA-based epoxy resin-Effects of a liquid rubber inclusion. Polymer:;8(6):1695-710.

[5] Gibson, RF. (2016.). Principles of composite material mechanics: CRC press.

[6] Ebrahimabadi Y, Mehrshad M, Mokhtary M, Abdollahi M. (2021). Studies of thermal, mechanical properties, and kinetic cure reaction of carboxyl-terminated polybutadiene acrylonitrile liquid rubber with diepoxy octane. Journal of Applied Polymer Science. 38(9):49932.

[7] Guild F, Kinloch A. (1995). Modelling the properties of rubber-modified epoxy polymers. Journal of materials science. 30(7):1689-97.

[8] Huang Y, Kinloch A. (1992) Modelling of the toughening mechanisms in rubber-modified epoxy polymers. Journal of materials science. 27(10):2753-62

[9] Jung H-S, Park Y, Nah C-W, Lee J-C, Kim K-Y, Lee CS. Evaluation of the Mechanical Properties of Polyether Sulfone-Toughened Epoxy Resin for Carbon Fiber Composites. Fibers and Polymers. 1-12.

[10] Kinloch AJ, Guild FJ. (1996). Predictive modeling of the properties and toughness of rubber-toughened epoxies. ACS Publications.

[11] Ramos VD, da Costa HM, Soares VL, Nascimento RS. (2005). Hybrid composites of epoxy resin modified with carboxyl terminated butadiene acrilonitrile copolymer and fly ash microspheres. Polymer Testing. 24(2):219-26.

[12] Riew CK, Siebert A, Smith R, Fernando M, Kinloch A. (1996) Toughened epoxy resins: preformed particles as tougheners for adhesives and matrices. ACS Publications.

[13] Wang F, Drzal LT, Qin Y, Huang Z. (2016). Enhancement of fracture toughness, mechanical and thermal properties of rubber/epoxy composites by incorporation of graphene nanoplatelets. Composites Part A: Applied Science and Manufacturing. 87:10-22.

[14] Zhang J, Deng S, Wang Y, Ye L. (2016). Role of rigid nanoparticles and CTBN rubber in the toughening of epoxies with different cross-linking densities. Composites Part A: Applied Science and Manufacturing. 80:82-94.

[15] Pearson R, Yee A. (1989). Toughening mechanisms in elastomer-modified epoxies. Journal of materials science. 24(7):2571-80.

[16] Pearson RA, Yee AF. (1986). Toughening mechanisms in elastomer-modified epoxies. Journal of materials science. 21(7):2475-88.

[17] Yee AF, Pearson RA. (1986). Toughening mechanisms in elastomer-modified epoxies. Journal of materials science. 21(7):2462-74.

[18] Riew CK. (1989). Rubber-toughened plastics: American chemical society.

[19] Ignatova T, Kosyanchuk L, Todosiychuk T, Nesterov A. (2011). Reaction-induced phase separation and structure formation in polymer blends. Composite interfaces. 18(3):185-236.

[20] Mathew VS, Sinturel C, George SC, Thomas S. (2010). Epoxy resin/liquid natural rubber system: secondary phase separation and its impact on mechanical properties. Journal of materials science. 45(7):1769-81.

[21] Moschiar S, Riccardi C, Williams R, Verchere D, Sautereau H, Pascault J. (1991). Rubber-modified epoxies. III. Analysis of experimental trends through a phase separation model. Journal of applied polymer science. 42(3):717-35.

[22] Verchere D, Sautereau H, Pascault J, Moschiar S, Riccardi C, Williams R. (1990). Rubber-modified epoxies. I. Influence of carboxyl-terminated butadiene-acrylonitrile random copolymers (CTBN) on the polymerization and phase separation processes. Journal of Applied Polymer Science. 41(3-4):467-85.

[23] Wise C, Cook WD, Goodwin AA. (2000). CTBN rubber phase precipitation in model epoxy resins. Polymer. 41(12):4625-33.

[24] Chikhi N, Fellahi S, Bakar M. (2002) Modification of epoxy resin using reactive liquid (ATBN) rubber. European Polymer Journal. 38(2):251-64.

[25] Ratna D. (2001). Phase separation in liquid rubber modified epoxy mixture. Relationship between curing conditions, morphology and ultimate behavior. Polymer. 42(9):4209-18.

[26] Thomas R, Yumei D, Yuelong H, Le Y, Moldenaers P, Weimin Y, et al. (2008). Miscibility, morphology, thermal, and mechanical properties of a DGEBA based epoxy resin toughened with a liquid rubber. Polymer. 49(1):278-94.

[27] Gledhill R, Kinloch A, Yamini S, Young R. (1978). Relationship between mechanical properties of and crack progogation in epoxy resin adhesives. Polymer. 19(5):574-82.

[28] Shan H-Z, Chou T-W. (1995). Transverse elastic moduli of unidirectional fiber composites with fiber/matrix interfacial debonding. Composites Science and Technology. 53(4):383-91.

[29] Dadian A, Rahnama S, Zolfaghari A. (2020). Experimental study of the CTBN effect on mechanical properties and mode I and II fracture toughness of a new epoxy resin. Journal of Adhesion Science and Technology. 34(22):2389-404.

[30] Tripathi G, Srivastava D. (2008). Studies on the physico-mechanical and thermal characteristics of blends of DGEBA epoxy, 3, 4 epoxy cyclohexylmethyl, 3', 4'-epoxycylohexane carboxylate and carboxyl terminated butadiene co-acrylonitrile (CTBN). Materials Science and Engineering: A. 496(1-2):483-93.

[31] Deb P, Ratna D, Chakraborty B. (1997). Carboxyl terminated poly (ethylene glycol) adipate modified epoxy network. I. Synthesis and thermal characterization. Journal of Polymer Materials(Netherlands). 14(2):189-94. 
[32] Pearson R, Yee Y. (1983). Polymer Materials Sci. Preprints, Amer Chemical Soc.186:316.

[33] Kim JK, Datta S. (2013). Rubber-thermoset blends: micro and nano structured. Advances in elastomers I: Springer. p. 229-62.

[34] Ratna D. (2007). Epoxy composites: impact resistance and flame retardancy: iSmithers Rapra Publishing.

[35] Najipoor M, Haroonabadi L, Dashti A. (2018). Assessment of failures of nitrile rubber vulcanizates in rapid gas decompression (RGD) testing: Effect of physico-mechanical properties. Polymer Testing. 72:377-85.

[36] Yahyaie H, Ebrahimi M, Tahami HV, Mafi ER. (2013). Toughening mechanisms of rubber modified thin film epoxy resins. Progress in Organic Coatings. 76(1):286-92.

[37] Saleh AB, Ishak ZM, Hashim A, Kamil W, Ishiaku U. (2014). Synthesis and characterization of liquid natural rubber as impact modifier for epoxy resin. Physics Procedia. 55:129-37.

[38] Kinloch A, Hunston D. (1987). Effect of volume fraction of dispersed rubbery phase on the toughness of rubber-toughened epoxy polymers. Journal of materials science letters. 6(2):137-9.

[39] Chen J-P, Lee Y-D. (1995). A real-time study of the phase-separation process during polymerization of rubber-modified epoxy. Polymer. 36(1):55-65.

[40] Kiefer J, Hilborn J, Hedrick J. (1996). Chemically induced phase separation: a new technique for the synthesis of macroporous epoxy networks. Polymer. 37(25):5715-25.

[41] Kim DS, Kim SC. (1994). Rubber modified epoxy resin. II: Phase separation behavior. Polymer Engineering \& Science. 34(21):1598-604. 